\title{
Longitudinal Relationships among Endogenous Testosterone, Estradiol, and Quetelet Index with High and Low Density Lipoprotein Cholesterols in Adolescent Boys
}

\author{
P. M. LASKARZEWSKI, J. A. MORRISON, J. GUTAI, P. R. KHOURY, AND C. J. GLUECK ${ }^{(39)}$ \\ Lipid Research, General Clinical Research, and CLINFO Centers, Departments of Medicine and Pediatrics, \\ University of Cincinnati, College of Medicine Cincinnati, Ohio; East Carolina University, School of Medicine \\ Greenville, North Carolina; School of Public Health, University of Pittsburgh College of Medicine, \\ Pittsburgh, Pennsylvania, USA
}

\section{Summary}

In a 1-year longitudinal study of 19 adolescent boys, our major aim was to assess whether, and to what degree, testosterone, estradiol, Quetelet index, and their interactions related to concentrations of high and low density lipoprotein cholesterol (HDLC, LDLC). During the 1-year followup, mean HDLC and estradiol levels fell and triglycerides, LDLC, Quetelet index, and testosterone levels rose. For large decreases in estradiol, increases in testosterone were associated with decreases in HDLC. These decreases in HDLC were moderated by small decreases in Quetelet index. For boys with small decreases in estradiol, as the changes in testosterone increased, the change in HDLC varied from an increase to a decrease, except in those boys who also had a small decrease in Quetelet index, for whom the change in HDLC was positive. The greatest increases in LDLC were observed in boys having the largest increase in Quetelet index and a small decrease in estradiol; however, as the decrease in estradiol became large, the positive association of Quetelet with LDLC was moderated or nullified. For boys having large decreases in estradiol, the LDLC/HDLC ratio changed from small increments to substantial decrements as testosterone increased. As the decreases in estradiol became smaller, increases in the change of testosterone moderated the decreases in the LDLC/HDLC ratio, and large increases in Quetelet index tended to diminish this moderation. As the change in testosterone increased, the change in triglyceride increased, unless the decrease in estradiol was small. The overall pattern of change of HDLC and LDLC during sexual maturation in boys can be associated with changes in testosterone, estradiol, and Quetelet index.

Abbreviations

E2, estradiol

HDLC, high density lipoprotein cholesterol

LDLC, low density lipoprotein cholesterol

$\mathbf{Q}$, Quetelet index

$T$, testosterone

TG, triglyceride

The decrement in HDLC during male adolescence has been postulated to result from increased $\mathrm{T}$ production $(16,18)$; however, there is a significant positive correlation between HDLC and $T$ in adult men $(13,15,25,30)$. In adults, pharmacologic doses of exogenous T lower HDLC $(2,11)$. The reasons for this dichotomy remain to be fully explicated but different interactions of $T$ and E2 during adolescence and adulthood may, in part, account for the opposite correlations of HDLC and T (18). For example, at the highest endogenous E2 levels, endogenous $T$ is inversely associated with HDLC in adolescent males (18) whereas lower E2 and $T$ levels in sexually mature men could be associated positively with HDLC

Prepubescent boys have, if anything, higher HDLC than girls $(3,28)$. The within-adolescence decrement in HDLC leads to the well recognized HDLC differential in sexually mature adults where men have lower HDLC, higher LDLC, and higher levels of TG than premenopausal women $(14,21)$. The adult male-female differences in lipoproteins (lower HDLC, higher LDLC, and higher TG) probably account, in part, for male-premenopausal female differences in atherosclerosis $(32,33,36)$. Understanding of the physiologic events during male adolescence $(5,26)$ that lead to a decrement in HDLC and to an apparent inverse relationship between $\mathrm{T}$ and HDLC $(16,18)$, has considerable physiologic importance, particularly because after sexual maturation, in adult men, $T$ is positively related to $\operatorname{HDLC}(13,15,25,30)$.

To examine the physiology of changes in LDLC, HDLC, TG, rapid physical growth, and sexual maturation, the Princeton School Maturation Study was initiated in 1976 (29). A randomly selected sub-group of the Princeton Prevalence Program was drawn (27-29), and annual measurements of lipids, lipoproteins, blood pressure, and physical growth were made in conjunction with assessments of sexual maturation as indicated by the Tanner Scale $(23,24)$. In an earlier longitudinal report on the findings of the first 3 years of followup in the Princeton School maturation study (29), the mid-Tanner decline in total cholesterol in boys was associated with a decrease in HDLC and a subsequent increase in total cholesterol in the higher Tanner stages was associated with an increase in LDLC. We speculated that these changes in lipoproteins were linked with increased endogenous $\mathrm{T}$ production (29).

In 1980, we added measurements of endogenous $\mathrm{T}$ and $\mathrm{E} 2$ to measurements of lipids and lipoproteins (18). Cross sectional studies of the relationships between endogenous T, E2, Q, which is defined as [weight $\left.(\mathrm{kg}) / \mathrm{height}^{2}(\mathrm{~cm})\right][1000]$ and lipids and lipoproteins were carried out. No single index of relative adiposity is optimal for all age-sex-race groups (19). We have previously shown that Quetelet is an adequate index for our Princeton School District population group (19). Using multiple regression analysis, with $\mathrm{E} 2, \mathrm{E} 2^{2}, \mathrm{~T}, \mathrm{~T}^{2}, \mathrm{Q}, \mathrm{Q}^{2}$, and their interactions as explanatory variables, $47 \%$ of the variance of HDLC $(P=0.006), 76 \%$ of the variance of LDLC $(P=0.0001), 87 \%$ of the variance of the ratio of LDLC to HDLC $(P=0.0001)$, and $56 \%$ of the variance TG $(P$ $=0.01$ ) could be explained (18). For higher levels of E2, there was an inverse association between HDLC and T. For those with the highest E2 levels, and at any given T level, the higher the Quetelet index, the lower the HDLC. Boys of median E2 levels had a slight 
Table 1. Sex hormones, lipoproteins, and quetelet indices in 19 boys in 1980 and $1981^{1}$

\begin{tabular}{|c|c|c|c|c|c|c|c|c|c|c|c|c|c|}
\hline $\begin{array}{l}\text { Sub- } \\
\text { ject }\end{array}$ & $\begin{array}{l}1980 \\
\text { Age }\end{array}$ & $\begin{array}{l}1981 \\
\text { Age }\end{array}$ & $\begin{array}{c}1980 \\
\text { Estradiol } \\
\text { (pg/ml) }\end{array}$ & $\begin{array}{c}\text { I981 } \\
\text { Estradiol } \\
(\mathrm{pg} / \mathrm{ml}) \\
\end{array}$ & $\begin{array}{c}\text { Difference in } \\
\text { estradiol } \\
1981-1980 \\
(\mathrm{pg} / \mathrm{ml}) \\
\end{array}$ & & $\begin{array}{c}1980 \\
\text { Testosterone } \\
\text { (ng/dl) }\end{array}$ & $\begin{array}{c}1981 \\
\text { Testosterone } \\
(\mathrm{ng} / \mathrm{dl})\end{array}$ & $\begin{array}{c}\text { Difference in } \\
\text { testosterone } \\
1981-1980 \\
(\mathrm{ng} / \mathrm{dl})\end{array}$ & $\begin{array}{c}1980 \\
\text { Quetelet }\end{array}$ & & $\begin{array}{c}1981 \\
\text { Quetelet }\end{array}$ & $\begin{array}{c}\text { Difference in } \\
\text { Quetelet index } \\
\text { 1981-1980 }\end{array}$ \\
\hline 1 & 14.8 & 15.8 & 23.6 & 5.0 & -18.6 & & 357.5 & 460 & 102.5 & 2.96 & & 3.24 & 0.28 \\
\hline 2 & 14.8 & 15.8 & 48.1 & 33.4 & -14.7 & & 363.0 & 301 & -62.0 & 2.92 & & 3.10 & 0.18 \\
\hline 3 & 14.8 & 15.8 & 18.8 & 34.5 & 15.7 & & 687.6 & 752 & 64.4 & 2.44 & & 2.36 & -0.08 \\
\hline 4 & 14.8 & 15.7 & 31.7 & 32.4 & 0.7 & & 753.4 & 942 & 188.6 & 2.31 & & 2.44 & 0.13 \\
\hline 5 & 14.9 & 15.9 & 32.1 & 5.0 & -27.1 & & 373.6 & 413 & 39.4 & 2.22 & & 2.16 & -0.06 \\
\hline 6 & 15.1 & 16.0 & 83.7 & 45.4 & -38.3 & & 565.4 & 908 & 342.6 & 3.01 & & 3.04 & 0.03 \\
\hline 7 & 15.4 & 16.4 & 58.4 & 31.9 & -26.5 & & 698.1 & 1204 & 505.9 & 1.89 & & 1.78 & -0.10 \\
\hline 8 & 15.5 & 16.4 & 17.0 & 29.6 & 12.6 & & 770.8 & 856 & 85.2 & 2.07 & & 2.16 & 0.09 \\
\hline 9 & 15.5 & 16.4 & 27.7 & 34.4 & 6.7 & & 1260.8 & 1109 & -151.8 & 2.10 & & 2.25 & 0.15 \\
\hline 10 & 15.6 & 16.6 & 27.4 & 36.2 & 8.8 & & 575.3 & 642 & 66.7 & 1.99 & & 2.11 & 0.13 \\
\hline $\begin{array}{l}\text { Sub- } \\
\text { jects }\end{array}$ & $\begin{array}{c}1980 \\
\text { LDLC/HDL } \\
\end{array}$ & & $\begin{array}{c}1981 \\
\text { LDLC/HDLC } \\
\end{array}$ & $\begin{array}{c}\text { Difference in } \\
\text { LDLC/HDLC } \\
\text { 1981-1980 }\end{array}$ & $\begin{array}{c}1980 \\
\mathrm{HDLC} \\
(\mathrm{mg} / \mathrm{dl})\end{array}$ & $\begin{array}{r}1981 \\
\mathrm{HDLC} \\
(\mathrm{mg} / \mathrm{dl})\end{array}$ & $\begin{array}{c}\text { Difference in } \\
\text { HDLC } \\
1981-1980 \\
(\mathrm{mg} / \mathrm{dl})\end{array}$ & $\begin{array}{c}1980 \\
\mathrm{LDLC} \\
(\mathrm{mg} / \mathrm{dl})\end{array}$ & $\begin{array}{c}1981 \\
\mathrm{LDLC} \\
(\mathrm{mg} / \mathrm{dl})\end{array}$ & $\begin{array}{l}\text { ce in } \\
C \\
980 \\
\text { li) }\end{array}$ & $\begin{array}{l}1980 \\
\mathrm{TG} \\
(\mathrm{mg} / \mathrm{dl})\end{array}$ & $\begin{array}{c}1981 \\
\mathrm{TG} \\
(\mathrm{mg} / \mathrm{dl})\end{array}$ & $\begin{array}{c}\text { Difference in } \\
\text { TG } \\
1981-1980 \\
(\mathrm{mg} / \mathrm{dl})\end{array}$ \\
\hline 1 & 3.38 & & 4.21 & 0.82 & 39 & 35 & -4 & 132.0 & 147.3 & 5.3 & 102 & 88 & -14 \\
\hline 2 & 2.83 & & 3.09 & 0.25 & 43 & 36 & -7 & 121.8 & 111.2 & 0.7 & 115 & 143 & 28 \\
\hline 3 & 0.93 & & 0.89 & -0.04 & 66 & 65 & -1 & 61.5 & 58.0 & 3.5 & 39 & 66 & 27 \\
\hline 4 & 1.74 & & 1.65 & -0.09 & 71 & 64 & -7 & 123.5 & 105.3 & 8.2 & 39 & 64 & 25 \\
\hline 5 & 1.56 & & 2.07 & 0.51 & 61 & 51 & -10 & 95.3 & 105.5 & 0.2 & 52 & 51 & -1 \\
\hline 6 & 1.88 & & 1.68 & -0.20 & 46 & 53 & 7 & 86.5 & 88.8 & 2.3 & 117 & 157 & 40 \\
\hline 7 & 1.64 & & & & 59 & 41 & -18 & 97.0 & & & 60 & & \\
\hline 8 & 1.08 & & 1.37 & 0.30 & 71 & 62 & -9 & 76.3 & 85.0 & 8.7 & 58 & 120 & 62 \\
\hline 9 & 1.21 & & 1.96 & 0.75 & 59 & 48 & -11 & 71.3 & 94.0 & 2.7 & 64 & 72 & 8 \\
\hline 10 & 1.14 & & 2.17 & 1.04 & 64 & 47 & -17 & 72.7 & 102.2 & 9.5 & 80 & 95 & 15 \\
\hline $\begin{array}{l}\text { Sub- } \\
\text { ject }\end{array}$ & $\begin{array}{l}1980 \\
\text { Age }\end{array}$ & $\begin{array}{l}1981 \\
\text { Age } \\
\end{array}$ & $\begin{array}{c}1980 \\
\text { Estradiol } \\
(\mathrm{pg} / \mathrm{ml})\end{array}$ & $\begin{array}{c}198 \mathrm{I} \\
\text { Estradiol } \\
(\mathrm{pg} / \mathrm{ml})\end{array}$ & $\begin{array}{c}\text { Difference in } \\
\text { estradiol } \\
1981-1980 \\
(\mathrm{pg} / \mathrm{ml}) \\
\end{array}$ & & $\begin{array}{c}1980 \\
\text { Testosterone } \\
\text { (ng/dl) }\end{array}$ & $\begin{array}{c}1981 \\
\text { Testosterone } \\
(\mathrm{ng} / \mathrm{dl}) \\
\end{array}$ & $\begin{array}{c}\text { Difference in } \\
\text { testosterone } \\
1981-1980 \\
(\mathrm{ng} / \mathrm{dl})\end{array}$ & $\begin{array}{c}1980 \\
\text { Quetelet }\end{array}$ & & $\begin{array}{c}1981 \\
\text { Quetelet }\end{array}$ & $\begin{array}{c}\text { Difference in } \\
\text { Quetelet index } \\
1981-1980\end{array}$ \\
\hline 11 & 15.8 & 16.8 & 21.0 & 11.9 & -9.1 & & 850.0 & 1130 & 280.0 & 1.93 & & 1.93 & 0.00 \\
\hline 12 & 16.4 & 17.3 & 27.2 & 16.2 & -11.0 & & 1202.6 & 1724 & 521.4 & 2.14 & & 2.27 & 0.13 \\
\hline 13 & 16.5 & 17.4 & 17.6 & 9.0 & -8.6 & & 516.2 & 614 & 97.8 & 2.35 & & 2.36 & 0.01 \\
\hline 14 & 16.8 & 17.6 & 39.7 & 10.1 & -29.6 & & 975.1 & 1075 & 99.9 & 2.23 & & 2.28 & 0.05 \\
\hline 15 & 16.8 & 17.8 & 61.4 & 5.0 & -56.4 & & 969.6 & 777 & -192.6 & 2.46 & & 2.61 & 0.15 \\
\hline 16 & 17.1 & 18.1 & 27.0 & 5.0 & -22.0 & & 1207.3 & 960 & -247.3 & 2.12 & & 2.05 & -0.07 \\
\hline 17 & 17.1 & 18.1 & 43.2 & 13.6 & -29.6 & & 723.8 & 955 & 231.2 & 2.81 & & 3.01 & 0.19 \\
\hline 18 & 17.7 & 18.6 & 25.0 & 5.0 & -20.0 & & 928.7 & 1006 & 77.3 & 2.13 & & 2.15 & 0.01 \\
\hline 19 & 17.9 & 18.9 & 23.0 & 9.7 & -13.3 & & 501.0 & 718 & 217.0 & 2.43 & & 2.52 & 0.09 \\
\hline
\end{tabular}




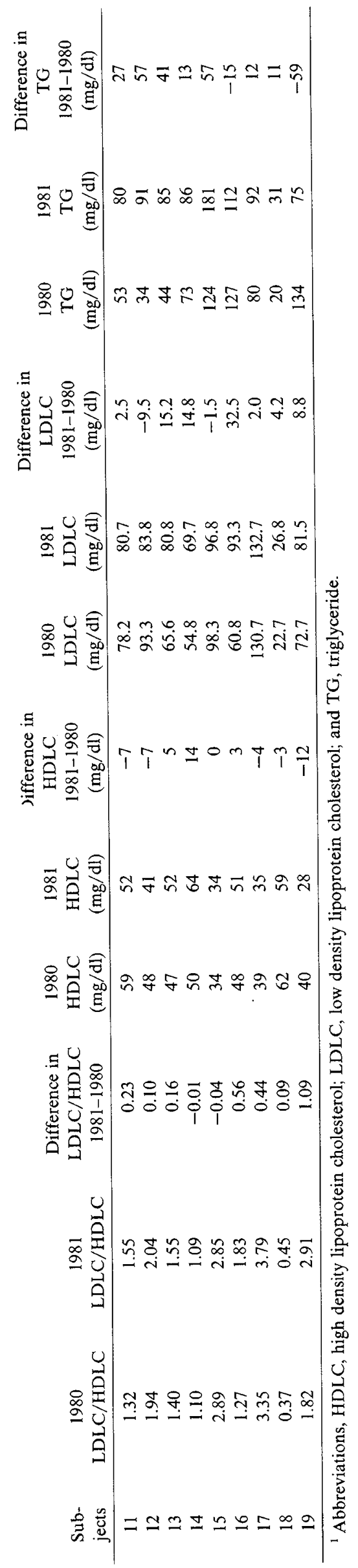

increase in HDLC as T increased. Boys with low E2 levels had sharper increases in HDLC with increases in $\mathrm{T}$. This cross sectional study (18) revealed that interactions of E2, T, and Q in adolescent males may lead, in some subjects, to changes in lipoproteins associated with atherogenesis (lower HDLC, higher LDLC to HDLC ratios) (12), and speculatively, to a higher risk of coronary heart disease later in life (33). We postulated that changes in Quetelet index, T, E2, and their interactions in boys during adolescence could account for a significant proportion of the dynamic changes observed in low and high density lipoprotein cholesterol (18).

In 1981 , we were able to restudy 19 of the 30 adolescent boys whom we had previously studied in 1980 (Tables 1 and 2); 11 of the 30 adolescent boys originally studied in 1980 did not have E2 values. The major aim of this analysis was to assess whether, and to what degree, T, E2, Q, and their interactions related to concentrations of HDLC, LDLC, and the ratio of LDLC to HDLC, longitudinally (over a l-year period) in boys undergoing sexual maturation. A second aim of this study involved an attempt to resolve the apparent dichotomy of a positive relationship of endogenous $T$ to HDLC in adult men $(13,15,25,30)$, and an inverse association of $\mathrm{T}$ to HDLC in many adolescent boys (16, 18).

\section{MATERIALS AND METHODS}

Study population. The Cincinnati Lipid Research Center has been conducting lipid surveys in the Princeton School District student population since April, 1973 (27-29). Following a collaborative NHLBI-LRC Protocol $(20,21)$, fasting plasma cholesterol and TG were measured in 6775 school children ages 6-17 years during Visit 1. Approximately 1500 of these children were studied a second time about 6 wk later (Visit 2), again following a collaborative NHLBI-LRC Protocol $(20,21)$, with measurements of lipids and lipoproteins.

Study protocol. After Visits 1 and 2, The Princeton Maturation Study was initiated in 1976 (29). A random subset of students in grades 5-12 drawn from the Visit 1 group were recalled for this assessment. At the 1976 screening, fasting cholesterol and TG (but not lipoproteins), blood pressure, height, and weight were measured (29). Data on Tanner Stage $(23,24)$ were collected. In 1980 and again in 1981, serum was obtained for measurement of $T$ and E2 $(1,7,17)$, as well as lipids and lipoproteins by collaborative Lipid Research Clinics' methodology (22).

In 1976, 529 students (74\% of eligible) participated. Of these 529 students, 250 had a Tanner Scale of less than 4 and were selected for followup. Including students lost to followup because of graduation or moving outside the school district, participation averaged $80 \%$ each year. Following the conventions of the Collaborative NHLBI-LRC Protocol (21), we excluded from this longitudinal report for 1980-1981, orientals (one student) and children who were admittedly nonfasting, or taking medications that might affect lipids and lipoproteins. In this report we present data for boys only; data on girls will be provided in a later separate publication.

Measurements of lipids, lipoproteins, testosterone, and estradiol.

Table 2. Mean (S.D.) and median lipid, lipoprotein, hormone levels, and Quetelet indices in 19 adolescent boys

\begin{tabular}{lccccc}
\hline & \multicolumn{2}{c}{ Yevels, and Quetelet indices in 19} & adolescent boys \\
\cline { 2 - 3 } \cline { 5 - 6 } & $\overline{\mathrm{X}} \pm$ S.D. & Median & & $\overline{\mathrm{X}} \pm$ S.D. & Median \\
\hline HDLC (mg/dl) & $52.9 \pm 11.4$ & 50 & & $48.3 \pm 11.5$ & 51 \\
LDLC (mg/d) & $85.0 \pm 28.4$ & 78.2 & & $91.3 \pm 26.5$ & 91.1 \\
LDLC/HDLC & $1.73 \pm 0.83$ & 1.56 & & $2.06 \pm 0.98$ & 1.89 \\
TG (mg/dl) & $74.5 \pm 35.5$ & 64 & & $93.8 \pm 37.3$ & 87 \\
T (ng/dl) & $751.6 \pm 283.8$ & 723.8 & & $870.8 \pm 325.9$ & 908 \\
E2 (pg/dl) & $34.4 \pm 17.6$ & 27.4 & & $19.6 \pm 13.9$ & 13.6 \\
Quetelet W/H & $2.34 \pm 0.35$ & 2.23 & $2.41 \pm 0.41$ & 2.28 \\
\hline
\end{tabular}


Blood sampling techniques for the maturation program were identical to those previously described for Visits 1 and $2(21,22$, 29). Plasma was taken after a $12-14-\mathrm{h}$ fast, and cholesterol, HDLC, LDLC, and TG levels were measured following the methods of the LRC Laboratory Methods Manual (22). When fasting blood was drawn for determination of lipids and lipoproteins, a second 10-cc aliquot was drawn in an anticoagulant-free tube; serum $T$ (17) and E2 (1) were quantitated by radioimmunoassay with specific antibodies following LH-20 Sephatex chromatography (7). Each column eluate was analyzed in triplicate for $T$ or duplicate for E2 and the means were reported. The within and between day coefficients of variation for $\mathrm{T}$ were $5 \%$ and $9 \%$, respectively for pools of 451 and $456 \mathrm{ng} / \mathrm{dl}$. For E2 the within and between day coefficients of variation were $13 \%$ and $11 \%$ respectively in pooled serum from males of 24 and $55 \mathrm{pg} / \mathrm{ml}$.

Statistical analyses. Relationships between T, E2, Q, their interactions, and lipids and lipoproteins were assessed using multiple regression analysis $(4,8)$. The combination of $E 2$ and $Q$ was examined because it is known that adipose tissue aromatizes androgenic hormones to $\mathrm{E} 2$ in vivo, and that obesity may affect sex hormonal function in adolescent boys (35). The distributions of the differences between 1980 and 1981 values $(\Delta)$ of HDLC, the ratio of LDLC to HDLC, LDLC, and TG were first assessed for normality. Appropriate variance stabilizing transformations were carried out where needed. Regression models were constructed with $\triangle$ HDLC, $\triangle$ LDLC, the change in the ratio of LDLC to HDLC, and $\Delta \mathrm{TG}$ separately as dependent variables (Fig. 1-4). The independent (explanatory) variables were chosen from race, $\Delta \mathrm{Q}, \Delta \mathrm{T}, \Delta \mathrm{E} 2,(\Delta \mathrm{Q})^{2},(\Delta \mathrm{T})^{2},(\Delta \mathrm{E} 2)^{2}$, and interaction terms of $\Delta \mathrm{Q}$, $\Delta \mathrm{T}, \Delta \mathrm{E} 2,(\Delta \mathrm{Q})^{2},(\Delta \mathrm{T})^{2}$, and $(\Delta \mathrm{E} 2)^{2}$ on the basis of $\mathrm{R}^{2}$, minimum mean squared error, and Mallow's $\mathrm{Cp}$ statistic for inclusion into the model $(4,8)$.

After selection of the best fitting models for $\triangle H D L C, \triangle L D L C$, $\Delta(\mathrm{LDLC} / \mathrm{HDLC})$, and $\Delta \mathrm{TG}$, we inserted values of $\Delta \mathrm{T}, \Delta \mathrm{Q}$, and $\Delta \mathrm{E} 2$, which were well within the extremes of their respective empirical distributions, into the models and obtained estimated values for $\Delta$ HDLC, $\triangle \mathrm{LDLC}, \Delta(\mathrm{LDLC} / \mathrm{HDLC})$, and $\Delta \mathrm{TG}$. Although we allowed the $\Delta \mathrm{E} 2, \Delta \mathrm{Q}, \Delta \mathrm{T}, \Delta \mathrm{HDLC}, \Delta$ (LDLC, $\Delta$ (LDLC/HDLC), and $\Delta \mathrm{TG}$ all to be continuous in our analyses, to display our results using continuous data would require a four dimensional plot; hence we plotted the two dimensional relationships between changes in lipoproteins and changes in testosterone

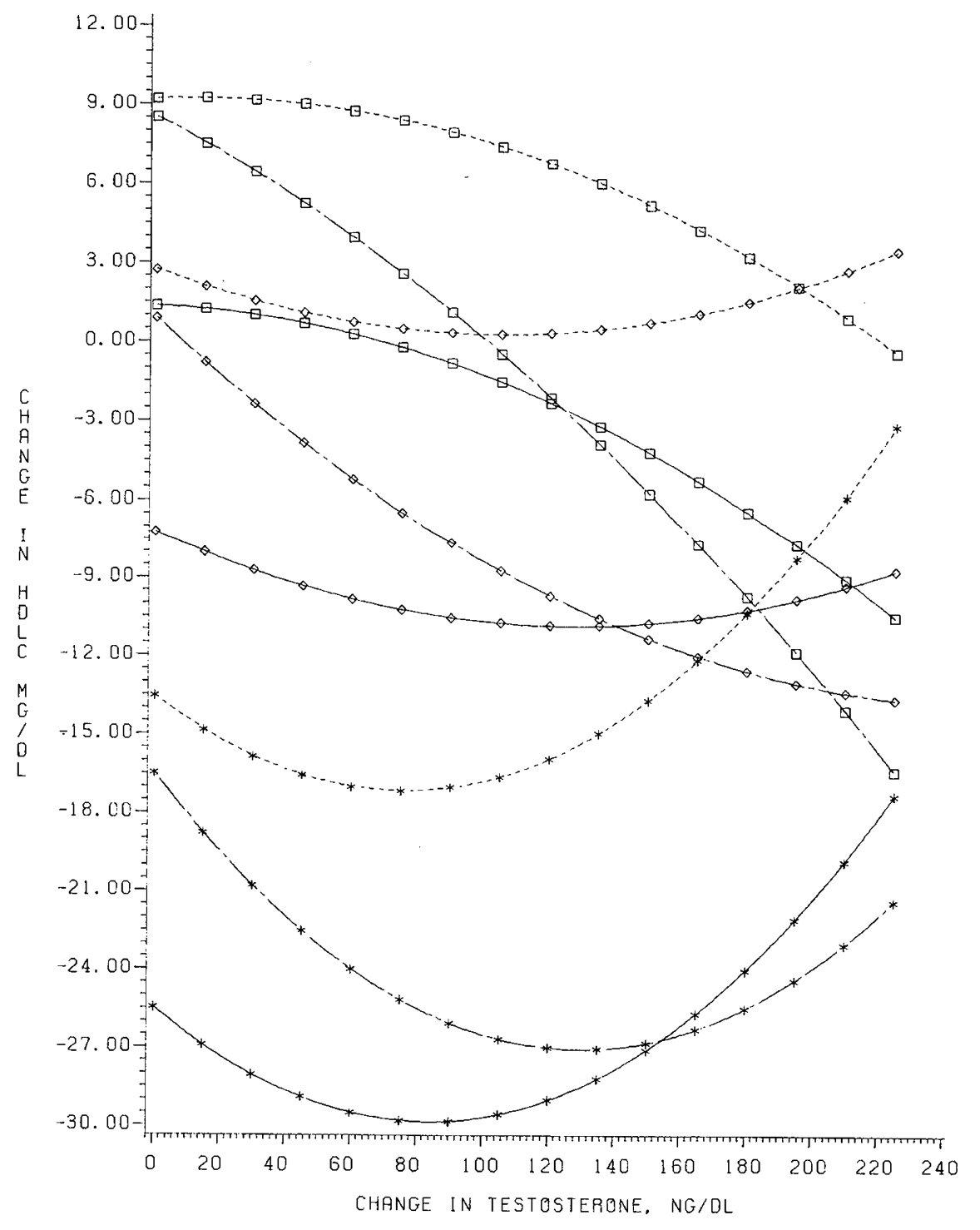

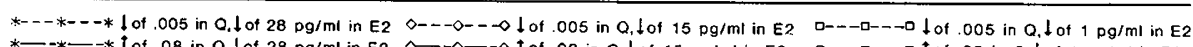

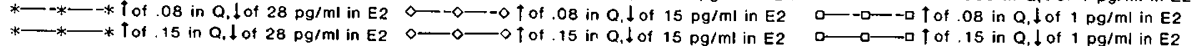

Fig. 1. Plot of predicted changes in high density lipoprotein cholesterol (HDLC) against changes in testosterone for different specified changes in Quetelet index and estradiol. The three different symbols (asterisk, diamond, and square) represent the three levels of change in estradiol, decreases of 28,15 , and $1 \mathrm{pg} / \mathrm{ml}$. The three different line types represent the three changes in Quetelet index, a decrease of 0.005 , and increases of 0.08 and 0.15 . 


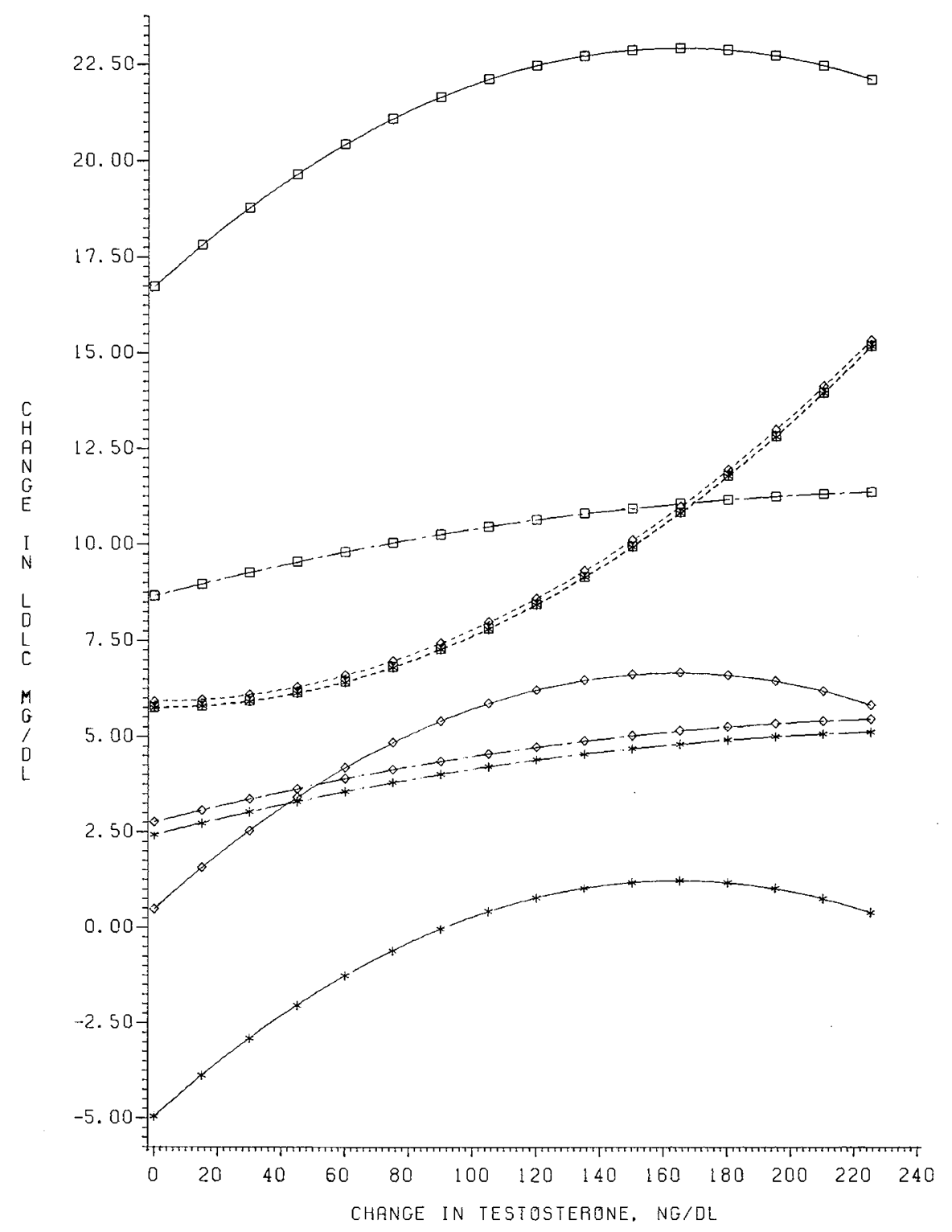

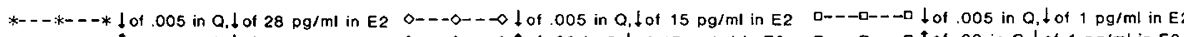

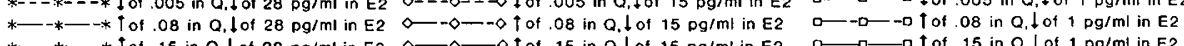

Fig. 2. Plot of predicted changes in low density lipoprotein cholesterol (LDLC) against changes in testosterone for different specified change in Quetelet index and estradiol. The three different symbols (asterisk, diamond, and square) represent the three levels of change in estradiol, decreases of 28,15 , and $1 \mathrm{pg} / \mathrm{ml}$. The three different line types represent the three changes in Quetelet index, a decrease of 0.005 , and increases of 0.08 and 0.15 .

for different values of changes of $\mathrm{Q}$ and $\mathrm{E} 2$ to facilitate understanding of the complex relationships of the lipoproteins to the hormones and to $\mathrm{Q}$. $\Delta \mathrm{T}$ was allowed to be a continuous variable. $\Delta \mathrm{Q}$ and $\Delta \mathrm{E} 2$ were each fixed at three levels to correspond to the lower, middle, and higher points of the distribution of $\Delta \mathrm{Q}$ and $\Delta \mathrm{E} 2$ in our data. For $\Delta \mathrm{Q}$ those values chosen were $-0.005,+0.08$, and +0.15 and for $\Delta \mathrm{E} 2$ the values were $-28,-15$, and $-1 \mathrm{pg} / \mathrm{ml}$. The use of lower, middle, and higher points for $\Delta \mathrm{Q}$ and $\Delta \mathrm{E} 2$ was for pictorial purposes only because the analyses were done with continuous data, as above. We chose this way of presenting the data because it allows focus on our primary interest, the association of $\mathrm{T}$ to lipoproteins in adolescent boys.

\section{RESULTS}

Sex hormones and lipids in 19 Boys in 1980 and 1981. Table 1 displays sex hormones, lipoproteins, and Quetelet indices in 19 boys initially sampled in 1980 and resampled in 1981. As they became 1 year older, HDLC fell in 14 of 19 boys, in one child there was no change, and in four children HDLC rose (Table 1). Mean HDLC fell $4.6 \mathrm{mg} / \mathrm{dl}$ between 1980 and 1981 (Table 2). Conversely, with increasing age, TG fell in only four boys and rose in 14 (Table 1). Mean triglycerides rose $19 \mathrm{mg} / \mathrm{dl}$ (Table 2). For LDL cholesterol, levels fell in five of the boys and rose in 13 (Table 1). Mean LDLC rose $6 \mathrm{mg} / \mathrm{dl}$ (Table 2). The ratio of LDLC to HDLC fell in five boys and rose in 13 (Table 1). The overall increase in the ratio of LDLC to HDLC was 19\% (Table 2 ); thus, the overall pattern of change in lipoproteins was a fall in HDLC, a rise in TG, a rise in LDLC, and an increment in the ratio of LDLC to HDLC (Table 2).

As displayed in Table 1 , there was considerable variation in $\mathrm{T}$ levels with increasing age, but mean T levels were $19 \%$ higher in 1981 (Table 2). Four of the 19 boys had lower T levels in 1981, and 15 had higher levels. Fourteen of the boys in 1981 had lower E2 levels, in one child there was a slight increase, and there were more substantive increases in four children (Table 1). Mean E2 levels in the group were reduced by $43 \%$ in 1981 (Table 2). Quetelet indices (weight divided by height ${ }^{2} \times 1000$ ) increased in 


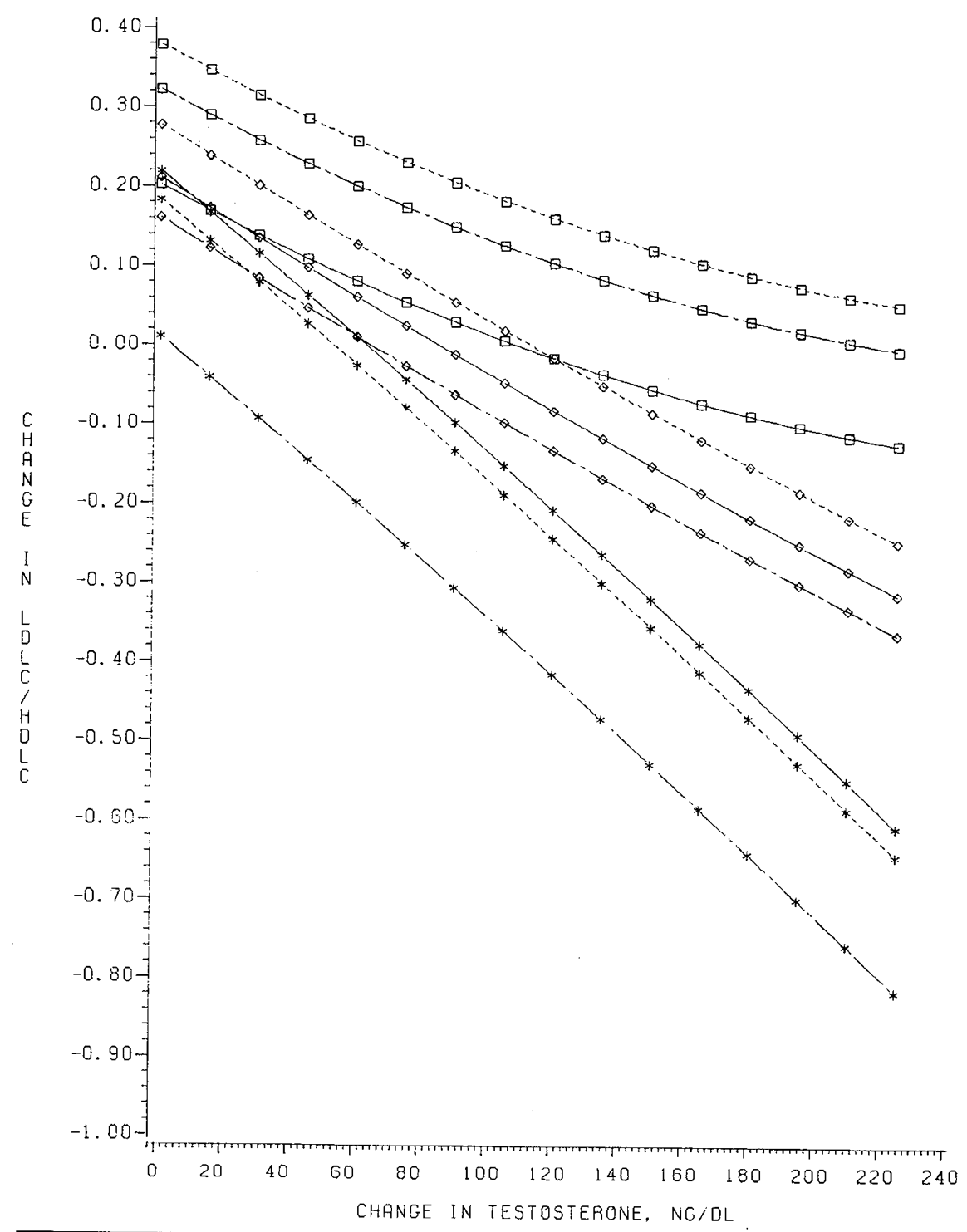

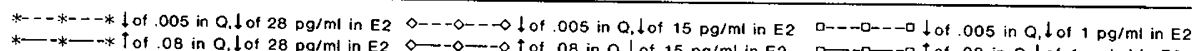

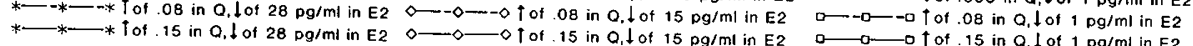

Fig. 3. Plot of predicted changes in LDLC/HDLC against changes in testosterone for different specified changes in Quetelet index and estradiol. The three different symbols (asterisk, diamond, and square) represent the three levels of change in estradiol, decreases of 28,15 , and $1 \mathrm{pg} / \mathrm{ml}$. The three different line types represent the three changes in Quetelet index, a decrease of 0.005 , and increases of 0.08 and 0.15 .

15 boys during the 1-year followup period (Table 1); mean Q increased only $3 \%$, however.

Longitudinal relationships between $H D L C$ and $T$. As displayed in Table 3, the model describing the relationship of $\Delta \mathrm{E} 2, \Delta \mathrm{T}, \Delta \mathrm{Q}$ and their interactions to $\triangle \mathrm{HDLC}$ accounted for $98.8 \%$ of the variance $(P=0.0004)$. In view of the large value of $\mathbf{R}^{2}$, the large number of explanatory variables found to be significant, and the small number of observations used in the model, the question arises as to whether the model was overparameterized. We were careful to ensure that this was not the case in any of our four models by carefully examining our results (i.e., overparameterization may be implied by the existence of large standard errors of the predicted values, which were not observed).

Figure 1 shows the relationship between changes in testosterone and changes in HDLC for specified changes in Q and E2, for adolescent boys studied first in 1980, and 1 year later in 1981. For boys with large decreases in $\mathrm{E} 2(28 \mathrm{pg} / \mathrm{ml})$, increases in T were associated with decreases in HDLC. The decreases in HDLC tended to become greater as the change in $T$ increased from 0 , but were reduced as changes in $\mathrm{T}$ became larger. For boys who had a small decrease in $\mathrm{Q}$, and a large decrease in $\mathrm{E} 2$, the decrease in HDLC was smallest.

For boys with small decreases in $\mathrm{E} 2(1 \mathrm{pg} / \mathrm{ml})$, as the changes in T from 1980 to 1981 increased, the change in HDLC varied from an increase to a decrease, except in those boys who also had a small decrease in $\mathrm{Q}$, for whom the change in HDLC was always positive. For boys who had moderate decreases in E2 $(15 \mathrm{pg} / \mathrm{ml})$ and moderate increases in $\mathrm{Q}$, as the change in $\mathrm{T}$ increased, the decrease in HDLC became larger. For boys with moderate decreases in E2, and small decreases in Q, HDLC increased; the increase was largest at small and large increases in $T$. Boys who demonstrated moderate decreases in E2 and large increases in Q had decreases in HDLC; the decreases were smaller at small and large increases in $\mathrm{T}$.

Longitudinal relationships between LDLC and T. As displayed in Table 2 , the multiple $R^{2}$ for the model describing the relationships of changes in sex hormones and Q to changes in LDLC was $0.902, P=0.0024$.

Figure 2 shows the relationship of changes in $T$ to changes in LDLC for specified changes in Q and E2. For boys demonstrating 


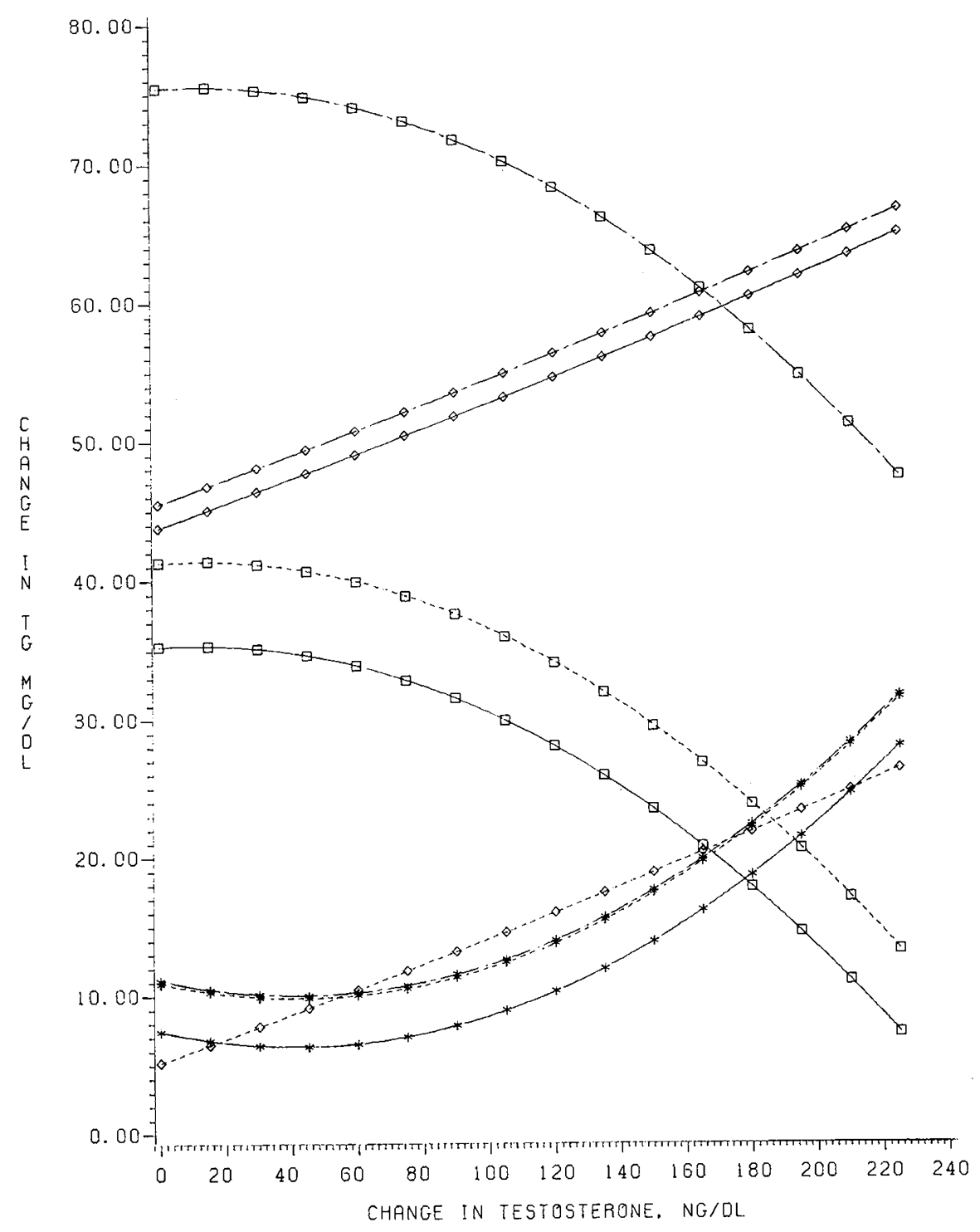

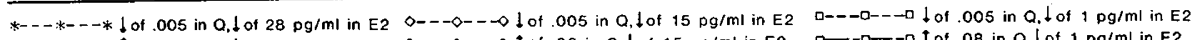

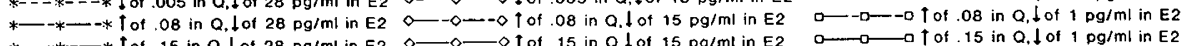

Fig. 4. Plot of predicted changes in triglyceride (TG) against changes in testosterone for different specified changes in Quetelet index and estradiol. The three different symbols (asterisk, diamond, and square) represent the three levels of change in estradiol, decreases of 28,15 , and $1 \mathrm{pg} / \mathrm{ml}$. The three different line types represent the three changes in Quetelet index, a decrease of 0.005 , and increases of 0.08 and 0.15 .

a decrease in $\mathrm{Q}$, as the increase in $\mathrm{T}$ became larger, the increase in LDLC became greater, irrespective, for the most part, of the change in E2. Boys who had small increases in $\mathrm{Q}$ had increases in LDLC, and these increases became larger as $T$ increased. The largest increase in LDLC for these boys having moderate increases in $\mathbf{Q}$ was accompanied by small decreases in E2.

The largest increases in LDLC were seen when $Q$ showed a large increase and E2 showed a very small decrease, and the magnitude of the increase in LDLC tended to become larger until the increase in $\mathrm{T}$ became rather large, at which point the increase in LDLC began to get smaller. A similar relationship between increases in T and increasing LDLC was seen in boys having large increases in $\mathrm{Q}$ and moderate decreases in $\mathrm{E} 2$, with the exception that the magnitude of increase in LDLC was smaller. For those boys who had large decreases in E2 and large increases in Q, LDLC decreased, unless the increase in $T$ was moderate to large, which then implied small increases in LDLC.

Longitudinal relationships between the $L D L C / H D L C$ ratio and $T$. As displayed in Table 3, the explanatory variables accounted for $99.7 \%$ of the variance of the change in the LDLC/HDLC ratio $(P=0.0001)$. Figure 3 shows the relationship of changes in $\mathrm{T}$ to changes in the LDLC/HDLC ratio for specified changes in $Q$ and E2. For boys having large decreases in E2, as $T$ increased, the LDLC/HDLC ratio changed from small increments to substantial decrements. As the decreases in E2 become smaller, increases in the change of $T$ moderated the decreases in the LDLC/HDLC ratio, and large increases in Quetelet index tended to diminish this moderation.

Longitudinal relationships between $T G$ and $T$. As displayed in Table 3, the model describing the relationship of changes in E2, $\mathrm{T}, \mathrm{Q}$, and their interactions to changes in TG accounted for $97.4 \%$ of the variance $(P=0.003)$.

Figure 4 shows that for boys with small decreases in E2, as the changes in $\mathrm{T}$ increase, the increases in TG decrease. The increases in $\mathrm{TG}$ in boys with small decreases in $\mathrm{E} 2$ are particularly marked when the boys also have a moderate increase in Q. For boys with large decreases in E2, as T increases, the TG increase becomes larger irrespective, for the most part, of the change in $\mathrm{Q}$. For boys 
Table 3. Relationships among changes in sex hormones, Quetelet index, high and low density lipoproteins, and triglyceride ${ }^{1}$

\begin{tabular}{|c|c|c|c|c|c|c|}
\hline $\begin{array}{l}\text { Dependent } \\
\text { variable }\end{array}$ & & Explanatory variables & & & $\mathrm{R}^{2}$ & $P$ (Model) \\
\hline$\overline{\mathrm{HDLC}}$ & $\begin{array}{l}(\Delta \mathrm{E} 2)^{2}+\dagger \dagger \dagger \\
\Delta \mathrm{E} 2 * \Delta \mathrm{T} \dagger+\dagger \dagger \\
\Delta \mathrm{E} 2 * \Delta \mathrm{Q} \dagger \\
\Delta \mathrm{E} 2 *(\Delta \mathrm{T})^{2}+\dagger \dagger \dagger\end{array}$ & $\begin{array}{l}(\Delta \mathrm{T})^{2} \dagger+\dagger \dagger \\
\Delta \mathrm{T}^{*} \Delta \mathrm{Q}+\dagger \dagger \dagger \\
\Delta \mathrm{T}^{*}(\Delta \mathrm{Q})^{2}+\dagger \dagger \dagger\end{array}$ & $\begin{array}{c}\Delta \mathrm{Q} \dagger \dagger \\
(\Delta \mathrm{Q})^{2} \dagger+\dagger\end{array}$ & Race $\dagger+\dagger$ & 0.988 & 0.0004 \\
\hline LDLC & $\begin{array}{l}\Delta \mathrm{E} 2 * \Delta \mathrm{Q} \dagger \\
(\Delta \mathrm{E} 2)^{2 *} \Delta \mathrm{Q} \dagger \dagger \\
\Delta \mathrm{E} 2 *(\Delta \mathrm{Q})^{2} \dagger\end{array}$ & $\begin{array}{l}(\Delta \mathrm{T})^{2} \dagger \\
(\Delta \mathrm{T})^{2 *} \Delta \mathrm{Q} \dagger \dagger \\
\Delta \mathrm{T}^{*}(\Delta \mathrm{Q})^{2} \dagger \dagger\end{array}$ & $(\Delta Q)^{2}+\dagger$ & Racet† & 0.902 & 0.0024 \\
\hline LDLC/HDLC & $\begin{array}{l}\Delta \mathrm{E} 2 \dagger \dagger \\
\Delta \mathrm{E} 2 * \Delta \mathrm{T}+\dagger \dagger \dagger \\
\Delta \mathrm{E} 2 * \Delta \mathrm{Q}+\dagger \dagger \dagger \\
(\Delta \mathrm{E} 2)^{2 *} \Delta \mathrm{T}+\dagger \dagger \\
\Delta \mathrm{E} 2^{*}(\Delta \mathrm{Q})^{2}+\dagger \dagger \dagger \\
\Delta \mathrm{E} 2^{*}(\Delta \mathrm{T})^{2}+\dagger \dagger\end{array}$ & $\begin{array}{c}\Delta \mathrm{T}+\dagger^{+} \dagger \\
(\Delta \mathrm{T})^{2}+\dagger \dagger\end{array}$ & $(\Delta Q)^{2}+\dagger$ & Racet† & 0.997 & 0.0001 \\
\hline TG & $\begin{array}{c}\Delta \mathrm{E} 2+\dagger \dagger \\
(\Delta \mathrm{E} 2)^{2} \dagger \dagger \\
\Delta \mathrm{E} 2^{*} \Delta \mathrm{T} \dagger \dagger \\
\Delta \mathrm{E} 2 * \Delta \mathrm{Q} \dagger \dagger \\
(\Delta \mathrm{E} 2)^{2 *} \Delta \mathrm{T} \dagger \dagger \\
(\Delta \mathrm{E} 2)^{2 *} \Delta \mathrm{Q} \dagger \dagger \\
\Delta \mathrm{E} 2^{*}(\Delta \mathrm{T})^{2}+\dagger \\
\Delta \mathrm{E} 2 *(\Delta \mathrm{Q})^{2} \dagger \dagger \\
\end{array}$ & $(\Delta \mathrm{T})^{2} \dagger \dagger$ & $\begin{array}{c}\Delta \mathrm{Q}+\dagger \dagger \\
(\Delta \mathrm{Q})^{2}+\dagger \dagger\end{array}$ & & 0.974 & 0.003 \\
\hline
\end{tabular}

\footnotetext{
'Abbreviations: $\Delta \mathrm{E} 2$, change in estradiol; $\Delta \mathrm{T}$, change in testosterone; $\Delta \mathrm{Q}$, change in Quetelet index; HDLC, high density lipoprotein cholesterol; LDLC, low density lipoprotein cholesterol; TG, triglyceride.

Interactions between explanatory variables are represented by an $*$ between the variables. e.g., $\Delta \mathrm{E} 2 * \Delta \mathrm{T}=$ interaction between the change in estradiol and the change in testosterone.

$\dagger P<0.05$.

扩 $P<0.01$

t† $P<0.001$

t†t $P<0.0001$.
}

with moderate decreases in $\mathrm{E} 2$, as $\mathrm{T}$ increases the TG increases become larger, but the magnitude of the increase in TG is much larger if the boy also shows an increase in $Q$.

\section{DISCUSSION}

During the 1-year followup period, the overall change in the 19 adolescent boys' lipids and lipoproteins involved a decrease in HDLC, an increase of TG, an increase in LDLC, an increase in the ratio of LDLC/HDLC, an increase in $T$, a decrease in $E 2$, and an increase in $\mathrm{Q}$

For boys with large decreases in $\mathrm{E} 2(28 \mathrm{pg} / \mathrm{ml})$, increases in $\mathrm{T}$ were, overall, associated with decreases in HDLC. Because we observed E2 levels falling with increased age and T levels, this inverse association of T with HDLC is consistent with the observations of Insull et al. (16) and with our earlier observation of decreasing HDLC accompanying increasing external sexual maturation as judged by the Tanner index (29). Reflecting the significant inverse association of Q with HDLC (19), for boys who had a small decrease in $Q$ despite a large decrease in E2, the decrease in HDLC was smallest. These longitudinal findings are similar to our cross-sectional data (18), where for boys with high levels of $\mathrm{E} 2,40 \mathrm{pg} / \mathrm{ml}$, there was a strong inverse association between HDLC and T. But in the cross-sectional data (18) for boys with low $\mathrm{E} 2(22 \mathrm{pg} / \mathrm{ml})$, there was a positive association of HDLC with $T$.

As it is known that adipose tissue aromatizes androgenic hormones in vivo to $\mathrm{E} 2(31,35)$ and that obesity may affect sex hormonal function in adolescent boys (35), the substantial association of Q, E2, T, and lipoproteins is not unexpected. In an earlier study, Bennion et al. (5) observed no significant correlations between the ratio of plasma $\mathrm{E} 2$ to $\mathrm{T}$ and any lipid parameters in 35 Pima Indian males. It is, however, hard to generalize from the studies of Bennion et al. (5), because Savage et al. (34), also studying Pima Indian adolescents, observed a decrease in choles- terol during adolescence (presumably due to a decrease in HDLC) whereas Bennion et al. (5) observed an increase in HDLC during adolescence.

The apparent paradox of an inverse association of HDLC with $T$ during adolescence $(11,18)$, and a positive association of HDLC with $T$ in sexually mature adult men $(13,15,25,30)$, may be resolved by our observations in adolescent boys who had small decreases in E2. For such boys, particularly where there was a small decrease in $\mathrm{Q}$, the change in HDLC was always positive as $T$ increased. The decrease in HDLC with increasing $T$ in boys with small decreases in E2 was observed when Q increased moderately to markedly, re-emphasizing the important inverse association of Q with HDLC (19); thus, given an interaction of T, Q, and E2, one might expect to see an inverse association of HDLC with $T$ during developing male sexual maturation, but a positive association of $T$ with HDLC in sexually mature adult males, given stable E2 levels. In this study, mean E2 levels were $34 \mathrm{pg} / \mathrm{ml}$ in 1980 , and $20 \mathrm{pg} / \mathrm{ml}$ in 1981 . These E2 levels were respectively higher and lower than mean levels in 12 middle aged sexually mature men whom we have recently studied $(28 \mathrm{pg} / \mathrm{ml})(10)$.

As our adolescent males became older, their LDLC rose; this increase was positively associated with $T$ levels. The greatest increases in LDLC levels were observed in boys having the largest increase in $\mathrm{Q}$ and a small decrease in E2. It is known that LDLC is positively associated with $\mathrm{Q}(19)$; however, as the decreases in E2 become large, the positive association of $\mathrm{Q}$ with LDLC is moderated or nullified. The largest increases in LDLC were thus seen when $Q$ showed a large increase and when E2 showed a small decrease, i.e., the pattern commonly seen in sexually mature adult young males in America today (10). In our cross-sectional survey (18) we observed similar relationships between LDLC and T, where, at low E2 levels, there was a positive association of LDLC with $\mathrm{T}$, but at high E2 levels, LDLC was negatively and curvilinearly related to T (18). The positive association of LDLC with T should also contribute to the relative difference in atherogenicity 
between men and women $(15,36)$ and, in certain situations, contribute to early premature heart disease (33).

For boys with increasing $\mathrm{T}$ levels, although the degree of change in the ratio of LDLC/HDLC became less positive, at some points in the $\mathrm{T}$ distribution this degree of change was positive. For boys having large decreases in E2, as $\mathrm{T}$ levels increased, the ratio of LDLC:HDLC changed from small increments to substantial decrements. As decreases in E2 became smaller in boys, and $T$ changed positively, the gradual decrease in the otherwise positive change of the LDLC:HDLC ratio was diminished, consistent with the increasing ratio of LDLC:HDLC with age in adult males (21).

During the 1-year followup there was an appreciable, rather uniform increase in TG levels; moreover, the magnitude of this increase was substantially affected by interactions of T, E2, and $\mathrm{Q}$. With small decreases in E2, as the changes in $\mathrm{T}$ increased, the magnitude of increases in TG was reduced. This observation is consistent with the inverse association of $\mathrm{T}$ with $\mathrm{TG}$ levels observed in sexually mature men $(13,25)$. Again, the data in our longitudinal study was consistent with our cross-sectional study where, at high $\mathrm{Q}, \mathrm{T}$ was inversely associated with $\mathrm{TG}$, whereas at low $\mathrm{Q}, \mathrm{T}$ was positively associated with $\mathrm{TG}$ in adolescent boys (18).

From this and other studies $(6,16,18)$ the overall pattern of change of HDLC and LDLC and TG (9) in boys during adolescence can be ascribed to changes in $\mathrm{T}, \mathrm{E} 2$, and $\mathrm{Q}$.

It seems likely, as speculated by Phillips (33) and Mendoza et al. (25), that abnormalities in $\mathrm{T}$ or the ratio of E2:T in adult men may be associated with relatively lower HDLC, relatively higher LDLC, and relatively higher TG, thus predisposing certain adult men to atherosclerosis. Recently, Zumoff et al. (37) measured levels of various sex hormones and hormone metabolites in normal men, in men with prior myocardial infarction, and in men with severe coronary artery disease but no infarction. Men with prior myocardial infarction had significantly higher 24 -h mean plasma concentrations of estrone, dehydroisoandrosterone and dehydroisoandrosterone sulphate than did normal men. Men with positive coronary arteriograms but no history of infarction, had values that did not differ from those of men with negative arteriograms (37). Mean $T$ levels did not differ between normal men and men postinfarction, and ranged between $421-533 \mathrm{ng} / \mathrm{dl}$, considerably lower than the mean levels in the adolescent males of our study (752 and $871 \mathrm{ng} / \mathrm{dl})$. Mean E2 levels $(29 \mathrm{pg} / \mathrm{ml})$ did not differ between normal men and men postinfarction, or in men with positive or negative coronary arteriograms (37). No data were provided on lipid and/or lipoprotein levels and hence, associations between E2, T, and lipids and lipoproteins similar to those observed by Phillips (33) could not be assessed.

Particularly in men with abnormalities of HDLC and/or TG, we speculate that abnormalities of $\mathrm{T}$ or the ratio of $\mathrm{E} 2$ to $\mathrm{T}$ may play a role in dyslipoproteinemia and in development of premature coronary heart disease. Future evaluations similar to those of Zumoff et al. (37), but including measurements of lipids, lipoproteins, and apolipoproteins, should provide further evidence relative to this speculation.

\section{REFERENCES AND NOTES}

1. Abraham, G. E., Hopper, K., Tulchinsky, D., Swerdloff, R. S., and O'Dell, W. D.: Simultaneous measurement of plasma progesterone, 17-OH-progesterone, and estradiol-17B by radioimmunoassay. Anal. Lett., 4: 325 (1971).

2. Applebaum-Bowden, D., Haffner, S., and Hazzard, W.: Increase in hepatic triglyceride lipase with Stanozolol. Circulation (Abstract), 64: IV-157 (1981)

3. Beaglehole, R., Trost, D. C., Tamir, I., Kwiterovich, P., Glueck, C. J., Insull W., and Christensen, B.: Plasma high density lipoprotein cholesterol in children and young adults. Circulation, 62: 83 (1980).

4. Belsley, D. A., Kuh, E., and Welsch, R. E.: Regression Diagnostics, New York: John Wiley and Sons. 1980.

5. Bennion, L. J., Howard, B. V., and Bennett, P. H.: Pubertal changes in plasmalipids and lipoproteins - lack of correlation with plasma estradiol-testosterone. Clin. Res., 26: A126 (1978)

6. Berenson, G. S., Srinivasan, S. R., Cresanta, J. L., Foster, T. A., and Webber, L. $\mathrm{S}$.: Dynamic changes of serum-lipoproteins in children during adolescence and sexual-maturation. Am. J. Epidemiol., 113: 157 (1981).

7. Carr, B. R., Mikhall, G., and Flickinger, G. L.: Column chromatography of steroids on sephadex LH-20. J. Clin. Endocrinol. Metab., 33: 358 (1971).

8. Draper, N. R. and Smith, H.: Applied Regression Analysis, 2nd Edition, (John Wiley and Sons, New York 1981).

9. Frerichs, R. R., Srinivasan, S. R., Webber, L. S., and Berenson, G. S.: Serum cholesterol and triglyceride levels in 3446 children from a biracial community. Circulation, 54: 302 (1976)

10. Frey, M. A. B., Doerr, B. M., Srivastava, L. S., and Glueck, C. J.: Endogenous testosterone and estrogen: relationships to lipids and lipoproteins in men on a controlled exercise program. Clin. Res., 30(2): 392A (1982).

11. Glueck, C. J., Stein, E. A., and Kashyap, M. L.: Persistent hypoalphalipoproteinemia during therapy of familial type $\mathrm{V}$ hyperlipoproteinemia. Artery, 5: 463 (1979).

12. Gordon, T., Castelli, W. P., Hjortland, M. C., Kannel, W. B., and Dawber, T. R. High density lipoprotein as a protective factor against coronary heart disease. Am. J. Med., 62: 707 (1977)

13. Gutai, J., LaPorte, R., Kuller, L., Dai, W., Falvo-Gerard, L., and Caggiula, A. Plasma testosterone, high density lipoprotein cholesterol, and other lipoprotein fractions. Am. J. Cardiol., 48: 897 (1981).

14. Heiss, G., Johnson, N. J., Reiland, S., Davis, C. E., and Tyroler, H. A.: The epidemiology of plasma high density lipoprotein cholesterol levels. Circulation, 62: $116(1980)$.

15. Hill, P., Wynder, E., Garbaczewski, L., Garnes, H., Walker, A. R. P., and Helman, P. Plasma hormones and lipids in men at different risk for coronary heart disease. Am. J. Clin. Nutr., 33: 1010 (1980).

16. Insull, W., Kirkland, R. T., Probstfield, J. L., Keenan, B. S., and Clayton, G. W. Control of HDL-cholesterol levels by testosterone in pubertal males. Circulation, 64: 113 (1981)

17. Lacerda, L., Kowarski, A., Johanson, A. J., Johanson, A., Athanasiou, R., Migeon, C.: Integrated concentration and circadian variation of plasma testosterone in normal men. J. Clin. Endocrinol. Metab., 37: 366 (1973).

18. Laskarzewski, P. M., Morrison, J. A., Gutai, J., Orchard, T., Khoury, P. R., and Glueck, C. J.: High and low density lipoprotein cholesterols in adolescent boys: Relationships with endogenous testosterone, estradiol, and Quetelet index. Metabolism, 32: 262 (1983)

19. Laskarzewski, P. M., Morrison, J. A., Mellies, M. J., Kelly, K., Gartside, P. S. Khoury, P., and Glueck, C. J.: Relationships of measurements of body mass to plasma lipoproteins in school children and adults. Am. J. Epidemiol., 111: 395 (1980).

20. Lee, V. A.: Individual trends in the total serum cholesterol of children and adolescents over a 10-year period. Am. J. Clin. Nutr., 20:5 (1967).

21. Lipid Research Clinics Population Studies Data Book. Volume I. The Prevalence Study. U.S. Department of Health and Human Services. NIH Publication \#80-1527, pp. 3-129, 1980

22. Manual of Laboratory Operation, Lipid Research Clinics Program, Vol. 2. Lipid and Lipoprotein Analysis. DHEW Publication No. (NIH) 75-678. Washington D.C., Government Printing Office 1974

23. Marshall, W. A., and Tanner, J. M.: Variations in the pattern of pubertal changes in boys. Arch. Dis. Child., 45: 13 (1970).

24. Marshall, W. A. and Tanner, J. M.: Variations in the pattern of pubertal changes in girls. Arch. Dis. Child., 44: 291 (1969).

25. Mendoza, S., Osuna, A., Zerpa, A., Gartside, P. S., and Glueck, C. J.: Hypertriglyceridemia and hypoalphalipoproteinemia in azoospermic and oligospermic young men: relationships of endogenous testosterone to triglyceride and high density lipoprotein cholesterol metabolism. Metabolism, 30: 481 (1981).

26. Milligan, C. A., Wilcox, E. B., and Galloway, L. S.: Serum cholesterol and physical characteristics of pre-adolescents and adolescents. J. Am. Diet. Assoc., 49: 303 (1966).

27. Morrison, J. A., deGroot, I., Edwards, B. K., Kelly, K. A., Mellies, M. J., Khoury, P., and Glueck, C. J.: Lipid and lipoproteins in 967 schoolchildren, age 6-17 years. Pediatrics, 62: 990 (1978).

28. Morrison, J. A., deGroot, I., Edwards, B. K., Kelly, K. A., Rauh, J. L., Mellies, M. J., and Glueck, C. J.: Plasma cholesterol triglyceride levels in 6775 school children ages 6-17. Metabolism, 26: 1199 (1977).

29. Morrison, J. A., Laskarzewski, P. M., Rauh, J. L., Brookman, R., Mellies, M. J., Khoury, P., de Groot, I., Kelly, K., and Glueck, C. J.: Lipids, lipoproteins, and sexual maturation during adolescence: The Princeton Maturation Study. Metabolism, 28: 641 (1979).

30. Nordoy, A., Aakvaag, A., and Thelle, D.: Sex hormones and high density lipoproteins in healthy males. Atherosclerosis, 34: 431 (1979).

31. Odel, W. D. and Swerdloff, R. S.: Male hypoganadism. West J. Med. 124: 446 (1976).

32. Perova, N. V., Gerasimova, E. N., Chernysheva, N. P., and Nikitina, R. N. A. Alteration of apoprotein of very low density lipoproteins from blood plasma in hypertriglyceridemia. Vopr. Med. Khim., 25: 185 (1979).

33. Phillips, G. B.: Relationship between serum sex-hormones and glucose, insulin and lipid abnormalities in men with myocardial infarction. Proc. Natl. Acad Sci. USA, 74: 1729 (1977)

34. Savage, P. J., Hamman, R. F., Bartha, G., Dippe, S. E., Miller, M., and Bennett, $P$. H. Serum cholesterol levels in American (Pina) Indian children and adolescents. Pediatrics, 58: 274 (1976).

35. Voors, A. W., Harsha, D. W., Webber, L. S., and Berenson, G. S.: Obesity and external sexual maturation-The Bogalusa Heart Study. Prev. Med., 10: 50 (1981).

36. Wallentin, $\mathrm{L}$.: Cholesterol ester metabolism in plasma during estrogen and antiandrogen treatment in men with carcinoma of the prostate. J. Lab. Clin. Med., 98: 906 (1981)

37. Zumoff, B., Troxler, R. G., O'Connor, J. O., Rosenfeld, R. S., Kream, J., Levin, 
J., Hickman, J. R., Sloan, A. M., Walker, W , Cook, R. L and Fukushima, D. K.: Abnormal hormone levels in men with coronary artery disease. Arteriosclerosis, 2: 58 (1982).

38. This study was carried out with approval of the Faculty Research Committee and signed informed consent was obtained.

39. Requests for reprints should be addressed to: Dr. Charles J. Glueck, General

Copyright $@ 1983$ International Pediatric Research Foundation, Inc. $0031-3998 / 83 / 1708-0689 \$ 02,00 / 0$
Clinical Research Center, Cincinnati General Division, 234 Goodman Street, C2-3, Cincinnati, Ohio 45267.

40. Supported in part by Lipid Research Clinic Contract NO1-HV-2-2914L, and by the General Clinical Research Center Grant RR00068-20

41. Received for publication August 11, 1982.

42. Accepted for publication December 8,1982 